\title{
The Dynamics of Gender: A Grassroots Perspective on Economic Resilience and Empowerment of the Tonga People in Kariba
}

\author{
Monica Monga ${ }^{1}$, Munyaradzi A Dzvimbo ${ }^{1}$, Tinashe M Mashizha ${ }^{2}$ \\ ${ }^{1}$ Department of Development Studies, Lupane State University, Zimbabwe \\ ${ }^{2}$ Community Capacity Building Initiative Centre for Africa (CCBICA), Zimbabwe \\ munyadzvimbo@gmail.com
}

\begin{abstract}
This paper examines the dynamics of gender-differentiated effects of economic resilience on rural livelihoods and infrastructure improvements of the Tonga people who predominantly resides in North Western Zimbabwe. The paper interrogates men and women's empowerment as well as their roles of transforming their lives through engaging in various economic activities and infrastructural development in Mola, Nyaminyami District, Zimbabwe. This study uses a qualitative research approach which is backed by both primary and secondary data collection methods which are underpinned by mixed methods approach involving observation, focus group discussions with community members and in-depth interviews with community leaders and key stakeholders. The study proffers that while economic resilience affects both men and women, it disproportionately affects the amount of work women have to do which has a profound bearing on their ability to innovate and transform their obsolete infrastructure at their disposal. Hence, the study recommends ways to foreground gender mainstreaming in order to address emerging gender related challenges emanating from stereotyping and prejudice, stakeholder engagement and partnerships in revamping existing infrastructure.
\end{abstract}

Keywords: Community development; economic; gender mainstreaming; indigenous; infrastructure.

\section{Introduction}

Sex refers to an individual's biological characteristics whether a person is male or female while gender refers to the different roles that are assigned to males and females within society, and the socially constructed relationship between men and women (Alston, 2013). Suffice to say, in terms of traditional gender roles, women are supposed to operate within the private, domestic sphere of the home and family, while men operate in the public world of politics and economics. Women are supposed to be nurturing, passive and subservient while men are expected to be aggressive, active and dominant (Bahadur et al., 2015).These gender roles result from society's interpretation of men and women's biological differences. These interpretations of the biological differences between men and women have become accepted as normal and natural. The problem is that these roles limit the human potential of both men and women, and create fundamental inequalities within society. This however has a bearing on the dynamics of economic emancipation of the Tonga people in North Western Zimbabwe. Gender inequality refers to an imbalance of power between men and women in society. This is reflected in the fact that women have less political power than men, less economic clout, they have less say within the community, and are subjected to gender-based violence both inside and outside the home. Around the world, women carry a double burden of paid labour and unpaid reproductive work in the home, and in almost every society, women are the poorest of the poor (Mercy Corps, 2014; Koesler, 2015; Demetriades and Esplen, 2015). However, key traditional gender roles for women have remained basically the same. Their gender roles have expanded to include those roles and responsibilities traditionally considered as men's. On the other hand, while men have dropped some roles and 
responsibilities that are traditionally considered as men's, they have been reluctant to do roles that are considered as women's. This has increased women's work burden.

The primary objective of the study was to assess and explore the empowerment trajectory and economic resilience of the Tonga people in Zimbabwe and how they have managed to cope and engage in their own traditional and modern economic activities with regards to their daily livelihood duties. The study sought to identify the gender roles allocation patterns in livelihoods labour and to systematically examine how the different roles and associated sexes are affected by stereotyping and prejudice.

\section{Review of Literature}

This study is grounded on the worldview theory, Dai (2012) states that culture involves far more than just music, dance, art and the like by pointing out that our culture is our worldview, that is, fundamental to our understanding of which we are, where we have come from and where we are going. It is everything in us and around us that defines us and shapes us. World-view can be viewed as several layers of culture. Elias (2013) explains it well when he argues that one helpful method is to view a culture, visualizing several successive layers, or levels of understanding, as one moves into the real heart of culture. Three layers of culture are: the behavior (what is done), the values (what is good or best), the beliefs (what is true) and the worldview (what is real). World-view signifies the image people have of the nature of the world and life and their place and responsibility within the greater whole. A world-view is all embracing and provides people with the big picture of the context within which they must live. Every person has a world view. People may not always be aware of the picture which determines the way they see, experience and live this life (Dankelman, 2010).

Culture is the superglue that binds people together and gives them a sense of identity and continuity, which is almost impenetrable (Duvvury et al., 2013). It can be portrayed as concentric circle with behavior on the other layer and world-view at the other. Elias (2013) likened world view to colored glasses through which people see themselves and the universe around them. Understanding world-views as the core of every culture explains the confusion that some people have at the level of beliefs. Oxfam (2014) highlight that world-view provides a system of beliefs which are reflected in one's actual values and behavior. Sometimes a new competing system of beliefs is introduced, like Christianity, but the worldview remains unchallenged and unchanged, so values and behavior reflect on the old belief system including perceptions of sickness and suffering.

The traditional African family is patriarchal where men are considered the heads of their households while women and children are expected to defer to men's authority (AroraJonsson, 2014). Polygamous marriages (multiple wives) are acceptable where the husband has the means to pay the lobolo (bride wealth) for each, and to sustain them properly. Women are anticipated to leave their families to live with their husband's family.

The study proffers a deep understanding of gender dynamics as well as an insight into economic resilience and empowerment of the Tonga people. The study further looks at various activities and livelihoods that have been implored and initiated in North-Western Zimbabwe were the Tonga people reside. Issues on poverty, education and approaches have been addressed in a bid to understand socio-economic dynamics. 


\subsection{Culture and Tradition}

It is vital to point out that culture is an identity although religion and culture are two separate concepts; there is a great deal of overlap between them. Traditional cultural practices have often found their way into religious systems, while religious beliefs influence the cultural life of communities. Women with no male children must rely upon husbands or other male relatives for land access (Schipper and Langston, 2014). Infertile women may be condemned and disrespected. Mothers with only female daughters may suffer neglect from their husbands, face opposition from in-laws, and be denied access to husband's property; their husbands may take other wives in an attempt to bear them male children (Dankelman, 2010).

In South Africa, the form of land tenancy and land tenure (communal tribal land allocation) has increased the uncertainty of women's right of access to land by only recognizing males as title holders. This has increased women's food insecurity. Women proposed an alternative since most men migrate to urban areas, they should have in place a system like a power of attorney which will enable them to make decisions as members of the household(Cornwall and Edwards, 2014; Doss and Kieran, 2014). In Zambia, although no legal restriction on land use exists, women have a difficult time obtaining land from land authorities. Under the statutory system, in some districts, married women must provide evidence of their husband's consent to obtain land, while unmarried women are often not recommended for allocation of land if they do not have children.

Polygamy, either de facto or de jure, was mentioned in eight PPA reports from Africa. It was generally regarded as a contributing factor of poverty in PPA reports, but not unambiguously. While polygamy is not officially recognized in Guinea Bissau and only monogamous marriages are legal, polygamy is widespread, mainly in the rural and Moslem environments. According to the same survey, 47 percent of husbands interviewed indicated that they wanted to be polygamous in order to have many children, and polygamy is widely practiced (Elias, 2013; Diarra et al., 2014). While polygamy is legal in Togo, the PPA report is critical of this household structure as an inherently patriarchal practice that legitimates the idea of women as property: Although the new constitution adopted in 1992 recognizes all citizens as equal before the law, traditions are difficult to change and the 1980 Family Code implicitly recognizes gender inequality by allowing polygamy and regulating thus legitimizing the bride price(Koesler, 2015).Polygamy leads to strained relations in the home and scarcity of resources. Polygamy is one of the defects; it is a terrible thing that someone with two acres of land has five wives. So many children share the little land and they all suffer (Oxfam, 2014).Emerging feminist actions in the region are directed at bringing existing socio-cultural ideas of gender into the open, challenging them and defending suggestions for acceptable alternative forms and resolutions (UNDP, 2014; Doss and Kieran, 2014). There is also a greater boldness in addressing the economic and political elements that determine social constructions of gender roles and women's status in African societies.

\subsection{Formal and Informal}

Too many children, especially those from poor families and those living in rural or remote areas, still lack access to a safe, nearby school or other quality learning opportunities (Castillejo, 2011). Working children, indigenous children, street children, refugee children, displaced children, orphaned children, trafficked children, child soldiers, and those who are physically challenged, living in conflict areas, or are affected by HIV or AIDS are not 
receiving an adequate education. Being female exacerbates an already difficult situation. In most developing countries, girls are less likely than boys to enroll in a school, or have their educational needs met through non-formal means. The best development investment available is not being fully utilized. Women are less literate than men, and female illiteracy has far reaching implications for development because illiteracy further marginalizes women in the public sphere (Demetriades and Esplen, 2015).However, women are often simply unable to participate in literacy programs. In Mali, for example, adult female participation in functional literacy programs was extremely weak because women's 17-hour work days prevented them from participating (Mercy Corps, 2014; Schipper and Langston, 2014).In a PPA from India, in a region where the number of girls attending school was less than half the number of boys, information distribution depends largely upon literacy; it is therefore not surprising that women are less aware than men of government programs or other services. Similarly, women are less aware of their legal rights, such as their right to own and inherit land (Elias, 2013; UNDP, 2014).Education costs include both school fees and costs associated with the loss of the child's labour. In addition, families are often asked for bribes and donations from schools. All these costs are a significant disincentive for many poor families. When weighing the costs, families frequently choose to educate boys in favour of girls.

\subsection{Poverty}

The pressures of poverty are experienced very differently by men and women. Men have experienced a threat to their social status, self-respect, and assurance in their economic role as providers for their family, through the loss of their cattle and through increased dependence on the informal earnings of their wife to meet basic household needs (WHO, 2013). Many instances were cited of men who had left the community and deserted their families because of debt they could not repay, or simply because they were unable to provide for their wives and children (Koesler, 2015; Demetriades and Esplen, 2015). One consequence of family breakdown is female-headed households. In some societies, female-headed households contend with the daily demands of economic survival in addition to facing ostracism from kinship systems that treat them as outcasts. The PPA report from Ghana shows that female-headed households tend to be genuinely socially marginal under the patrilineal kinship systems that prevail in the north (Oxfam, 2014).

It is widely accepted that female-headed households are more likely to be poor than male headed households (Carr and Thompson, 2014; Doss and Kieran, 2015). Divorced women are another prominent category of female heads of households, and they are particularly vulnerable to poverty. A man may take his social networks with him, leaving his ex-wife to cope only with her own. In addition, a divorced woman typically has restricted access to the very basic household necessities such as housing and land for food production. Divorced women's access to income is hampered by a range of factors including lack of child support from the ex-husband or his family (Elias, 2013; Oxfam, 2014).Despite modest progress in some countries, the post-colonial state has been unable to establish rights-based political and economic systems of governance that would facilitate consolidation of statebuilding and promote economic development. 


\subsection{Gender Relations in Traditional Institutions}

Gender relations in Africa in general, and women's participation in decision-making in particular, vary from one community to another and it is not clear how much of the discrepancy is associated with differences in the traditional political systems that prevail on the continent (Dai, 2012; Carr and Thompson, 2014). However, part of the discrepancy seems to be related to whether or not women are engaged in the production of valued goods that would empower them economically and whether the community has a matrilineal or patrilineal social organization. In general, women who control wealth or who are engaged in the creation of high value products have greater access to decision making power comparative to women who do not have economic independence. In most cases, the position of women in matrilineal societies also seems to be better than those in patrilineal societies, although in some matrilineal societies, such as the Berbers, Tuareg, and the Shaho of Eritrea, women neither participate indecision- making nor have inheritance rights.

\subsection{Participation in the Labour Market}

The participation of women in the work force is an indicator of female labour supply to the market sector that reflects the share of women willing (or forced) to combine paid activities with traditional unpaid activities in the household (Castillejo, 2011; Cornwall and Edwards. 2014). Being part of the labour force does not mean that women are integrated into gainful activities because the labour force includes both employed and unemployed men and women. Although the evolution of female participation in Latin American labour force has its own features, it replicates similar patterns of women's incorporation into paid employment in other regions. There are clear indications that over the past decades two important sex differentials in the labour market have narrowed in all Latin American countries, with averages moving closer to those of industrial countries. First, data for 1997-2007 confirm the upward trend in Latin American women's participation in labour, female participation in urban labour force rose from 47 to 53 per cent on average, while male participation decreased from 82 to 79 per cent (Oxfam, 2014). Consequently, gender gap in labour participation rates decreased from 35 to 26 percentage points. A second improvement refers to the reduction in male-female labour earning gaps on the aggregate, for all individual Latin American countries. However, due to their role in the reproductive sector, women work less hours in paid work, and when to controlled working hours, the wage gap is still considerable. Pronounced as these changes have been, we are still far from a convergence since average figures hide discrepancies within groups with cross-cutting influences of social class, race, ethnicity, rural-urban residence, migrant status. Latin American women are still far from facing equal opportunities in accessing, remaining and progressing in the labour market as compared to men. In addition, in spite of a higher rate of female participation there remain important gaps in terms of employment levels as well as in the quality of employment (formal versus informal employment), salary levels, professional training, and reduction in occupational segmentation (WHO, 2013). Higher levels of education by women have also resulted in increasing demands on women's training in the hiring process as compared to men. Women have always been suppressed and alienated in terms of being working opportunities. Hence, girl child in the Mola is not seen as liable contender hence, she is only seen as destined to get married. Most girls are educated and sponsored by Campaign for Female Education (Camfed) an NGO which has done extremely well to capacitate and enhance the girl child. 


\section{Research Method}

A primary and secondary data source was collected thorough key informants from different villages in Nyaminyami Rural District of Zimbabwe where the Tonga are predominantly found. Documents such as media and reports from Non-Governmental Organisations (NGOs) were reviewed. The data collected wasanalyzed using content and textual analysis. The main reason was to dissever and offer new understanding and interpretation of gender dynamics as well as economics resilience of the Tonga people in Zimbabwe used to develop this study.

\section{Discussion}

\subsection{Access to and Control over Assets and Resources}

The study reveals that crops that are for household consumption and that bring little cash belong to women, whereas those that bring 'good cash' or remuneration are men's crops. However the Tonga men mostly do not engage themselves in strenuous work they leave work to be done by women while they go to drink beer and enjoy social discussions. This arrangement notes with the roles that are expected of men and women. Statistics from focus group discussions and key informant interviews shows that the classification of crops as men's and women's has repercussions on the investment dedicated to the crop and ultimately the importance attached to it(Doss and Kieran, 2014; UNDP, 2014). This investment includes size of land under cultivation, quality of seed, fertilizers, labour and even attention given to the crop. However, Mola in Nyaminyami district of Kariba, where the majority of the Tonga resides is prone to wildlife animals and there is shortfall of arable land. Other significant assets such as land is also registered in the name of the man. Men also own farming implements and other tools such as scotch carts, wheelbarrows, knapsacks, harrows, hoes, axes, pliers and spanners. Women cannot lend these in the absence of the man (Demetriades and Esplen, 2015). On the other hand men cannot also lend kitchen ware in the absence of women. Some progress has been made in incorporating women in communitybased decision-making structures; this has been greatly enabled by NGOs such as Save the Children. Most women in the Tonga community complained during the interviews that although they have been incorporated into decision making structures, in some instances, it has been cosmetic as it is difficult to influence decisions during meetings. This was particularly the case with structures that were chaired by traditional leaders such village heads and chiefs.

\subsection{Deviations in Gender Rights}

While their impact on the patrilineal and matrilineal social organizations is unclear, education and urbanization, along with active state involvement in superseding traditional marriages with legal marriages, have led to some improvements in women's conditions. Advancement in improving the inheritance rights of children and in rising the age of marriage by promoting mass education has been made. However, less than 50 per cent of the African population lives in urban areas and only roughly the same ratio is literate (Diarra et al., 2014). Thus, many of the contrivances that subject women to oppression, including abduction, 
organized marriages without the consent of the bride, and marriage at an early age, are still widely practiced. In fact, organized marriages have been rampant within the Tonga community and it has gone for long unsolved and this continued to affect the level of empowerment of women.

Value and equal opportunity in education are inseparably linked (UNDP, 2014).Poorer marginalized children, who are more likely to have illiterate parents and less access to reading materials in the home are more dependent on their teachers for their learning. As a result, poor instruction perpetuates inequities because it is more often the most marginalized children who become school leavers, either through failure or voluntary dropping out mainly as a result that parents would not be willing to support them. This study has exposed that girls seem to be more subtle to school quality than boys and that the quality of teachers has a greater impact on the demand for girls' education than for boys. A study in Kenya concluded that factors considered under opportunities to learn chores, homework, tutoring, punishment, sex ratio, and class size have slightly different effects on girls than boys (Oxfam, 2014).

\subsection{Education in Retrospect}

Elias (2013) attests to the fact that the variation of sex roles was pointedly brought to the fore in mantoombwa, a popular game among Tonga children. In this imaginary game, a child built themselves play houses on the outskirts of the village. In the building process, boys did the work that was generally done by grown-up men in hut-building. They went to the bush and cut poles and constructed huts. The girls undertook women's work, involving cutting grass for thatching the huts and preparing food for the working men. When the hut is complete, boys pretended to herd cattle or hunt small birds to be cooked by girls. If one is a good girl that day her mother, would give her salt, meat or vegetables for mantoombwa. At, the end of play the girls bring food to their mothers to taste. If it was well cooked, the mother would praise the girl. Girls' education came to an end with puberty rites. These are organized when girls reached the age of fourteen or fifteen. A very significant part of the puberty ceremony is confinement of the girl into the house of some relative. The period of confine men varied between six weeks and two months in different parts of Tonga-land; during which girls attaining maturity were subjected to an intensive training given by senior women of the community (Harper et al., 2014; Mercy Corps, 2014). This part of girls' education is entirely controlled by women. The puberty rite had scope for biological, social and moral education. The physical education comprised the teaching of healthy sex habits and the knowledge of the procreation process. The social part of the training dealt with the rights and obligations of women in relation to the whole community, while moral training involved instructions in the art of self-discipline and control and trial of courage. Dai (2012) points out that older woman tried to reform the girls of the blemishes they had earlier observed in them while nurturing during their cultural social gatherings. If a girl had been impolite, she is rebuked and even beaten.

\subsection{Sexuality and Imperialism}

The history of the African female character has been associated to the cosmic development of colonialism, as the sex and gender role conflicts in post-colonial Zimbabwe are partly as a result of social constructions that ascended during the colonial period (Alston, 2013; UNDP, 2014; Koester, 2015). Thus, African political economies were tied to the West, and Zimbabweanwas given increased recognition in political and profit able spheres 
comparative to women. Furthermore, after colonization, hierarchical gender roles and discriminatory relationships in politics, economics, religion and culture have tended to be incessant. Zimbabwean women's scuffle against gender asymmetry and disparity is often pronounced in terms of the relationship between public and private spheres. In colonial Zimbabwe, female subservience took sophisticated forms grounded in traditional culture and executed through this domestic-public dichotomy. In many historical African societies, male and female roles were peculiar to the original social patterns and ideologies of those societies, but these became reconfigured around the edges as the society changed and evolved. The imposition of Western entrepreneurship and political hegemonies changed the dynamics of gender and sexuality in many colonized societies with the result that the historical and contemporary dynamics of the African state, and its approach to gender issues, have been different at different times (Fordham, Gupta, Akerkar and Scharf, 2011; WHO, 2013; Koester, 2015).

\subsection{Conceptualising Rights: Female Empowerment and Economic Resilience}

From the onset, the pressure to democratize and open up unrestricted participation to women, as well as protect their rights, has been externally derived. This has produced female responses that have grown out of a mixture of indigenous Zimbabwean experiences and colonial interventions (Elias, 2013; Schipper and Langston, 2014). Women actually have started to contest existing stereotypes, as well as to verbalize and exhibit their visions of gender roles in the country on their own terms. In fact, Tonga have now become more vocal about social, personal, cultural, religious and political challenges. The identical human-sexual rights awareness in sub-Saharan Africa has also caused political struggles for increased participation by women and dealing with the dilemma of having to respond to the persistent gender hierarchy. The Zimbabwean discourse has not grown out of the individualism within capitalist developing societies that brought about the women's rights are human rights agenda and shaped the movements in the United States, Britain and other European countries. It is now possible for women in these regions to engage in unrestrained discourses on the analysis or reinterpretations of the concepts of gender justice and roles, especially on issues related to women's rights (Castillo, 2011; Doss and Kieran, 2014). What this implies is that there is currently a new social crusade engaged in public information regarding the reconceptualization of women's identities. This is surely a big step forward. The novel and encouraging aspect of this development is that women are not only engaged in gaining access to the political or economic spheres of the state, but are engaged in redefining the meaning of gender and human rights in their societies. For the first time, women are articulating their aspirations and expectations in their own right.

\section{Conclusion}

It is in this realm that throughout the African continent and precisely Zimbabwean women has become more conscious of their rights as women, and of the requisite to address their subordinate positions in unrestricted and sequestered life. There is a new willingness among African women to strategize for change and be more specific in their goals and modes of operation for achieving a new gender compact. It has become clear that as women are still struggling to understand the patrimonial autocracy which most African states have experienced and why these conditions have affected mostly rural women more negatively 
than men. Women are questioning men's conceptual perceptions of women as nurturing, acquiescent, subordinate and familial and not as people with equal capabilities and rights. More so, Tonga women are challenging the prejudiced relationships that exist in their societies, the cultural models or compacts that continue to influence their lives, and the deep social issues that are affected by ethnic, political, religious and economic crisis (Dai, 2012). Whilst reassessing their positions, most women are nonetheless aware that a strong strand of cultural continuity connects their lives and the experiences of earlier generations. Although the detotalisations and de-specializations of postmodernism, coupled with the post-colonial's privileging of cultural pluralism and frameworks, have unsettled the foundations of cultural authenticity. This new mood of African feminism considers the convergence of the submultiples identities and their alignment with cultural expectations and interests. They know that to be taken seriously, the approach should not be to develop radical theories but theories to which such responses and deliberations pose no threat. Instead of attempting to eliminate sexism, or transform patriarchy into sexually neutral frameworks, the civic society must be realistic and aim at establishing unique discourses, based on knowledge of their unusual system that can be profoundly used to articulate her position. The tenacity of authentic clashes with Western feminist ideologies necessitates the inquiry into the meaning, nature, modalities and possibilities of a feminist epistemology fashioned on its own terms. This approach enables a cultural reading' that is focused on the power relations that work through constructions of masculinities and femininities.

\section{References}

Alston, M. (2013). Gender Mainstreaming and Climate Change. Women's Studies International Forum, 287-294.

Arora-Jonsson, S. (2011). Virtue and vulnerability: Discourses on Women, Gender, and Climate Change.Global Environmental Change, 744-51.

Bahadur, A., Wilkinson, E., \& Tanner, T. (2015). Resilience frameworks: A review. London: Overseas Development Institute.

Carr, ER., \& Thompson, MC. (2014) Gender and Climate ChangeAdaptation in Agrarian Settings: Current Thinking, New Directionsand Research Frontiers. Geography Compass, 182-197.

Castillejo, C. (2011) Building a State that Works for Women. Madrid: FRIDE.

Cornwall, A., \& Edwards, J. (eds.) (2014). Feminisms, empowermentand development: changing women's lives. London: Zed Books.

Dai, A. (2012). Increasing Drought Under Global Warming in Observations and Models. Nature Climate Change, 52-58.

Dankelman, I. (2010). Gender and Climate Change: An Introduction. London: Earth scan.

Demetriades, J.\& Esplen, E. (2015). The Gender Dimensions of Poverty and Climate Change Adaptation. IDS Bulletin, 24-31.

Diarra, D.M., Madougou, D.,\& Diouf, A. (2014) Food Crisis, Gender, and Resilience in the Sahel. Lessons From The 2012 Crisis in Burkina Faso,Mali, and Niger. Oxfam: Research Report. Oxford.

Doss, C., \& Kieran, C. (2014). Standards for collecting sex-disaggregated data for gender analysis: A guide for CGIAR researchers. Washington: Gender and Agriculture Research Network. 
Duvvury, N., Callan, A., Carney, P., \& Raghavendra, S. (2013) Intimate partner violence: Economic costs and implications for growth and development. Washington: The World Bank Group.

Elias, M. (2013). Practical Tips for Conducting Gender Responsive Data Collection. Rome: Bio-diversity International.

Fordham, M., Gupta, S., Akerkar, S., \& Scharf, M. (2011). Leading Resilient Development: Grassroots Women's Priorities, Practices and Innovations. New York: Groots

Harper, C., Nowacka, K., Alder, H., and Ferrant, G., (2014) Measuring women'sempowerment and social transformation in the post-2015 agenda. London: ODI/OECD

Koester, D. (2015). Gender and Power. Development Leadership Program Concept Brief .http://publications.dlprog.org/gender\&power.pdf Accessed 2 June 2018

Mercy, C. (2014). Rethinking Resilience: Prioritizing Gender Integrationto Enhance Household and Community Resilience to Food Insecurity in the Sahel. Portland: Mercy Corps.

Oxfam. (2014). Quick Guide to Gender-Sensitive Indicators.Oxford: Oxfam GB.

Schipper, L., \& Langston, L. (2014). Gender Equality and Climate Compatible Development Drivers and Challenges to Peopleempowerment: Literature Review. London: CDKN/Overseas Development Institute

UNDP. (2014). UNDP Gender Equality Strategy 2014-2017: The Future WeWant: Rights and Empowerment. New York: UNDP.

World Health Organization. (2013). Global and regional estimates of women: prevalence and health effects of intimate partner violenceand non-partner sexual violence. Geneva: World Health Organization. 